\title{
Effect of graphene nanoplatelets on the mechanical and gas barrier properties of woven carbon fibre/epoxy composites
}

\author{
Xudan Yao, ${ }^{1, \star}$, Thomas P. Raine ${ }^{1}$, Mufeng Liu ${ }^{1}$, Muzdalifah Zakaria ${ }^{2}$, Ian A. Kinloch ${ }^{1}$, and \\ Mark A. Bissett ${ }^{1}$ \\ ${ }^{1}$ Department of Materials, Henry Royce Institute and National Graphene Institute, University of Manchester, Oxford Road, \\ Manchester M13 9PL, UK \\ ${ }^{2}$ Petronas Research Sdn. Bhd., Lot 3288 \& 3289, Off Jalan Ayer Itam, Kawasan Institusi Bangi, 43000 Kajang, Selangor Darul Ehsan, \\ Malaysia
}

Received: 14 May 2021

Accepted: 14 August 2021

Published online:

5 September 2021

(C) The Author(s) 2021

\begin{abstract}
Carbon-fibre-reinforced polymer (CFRP) composites are promising materials for non-metallic pipe applications in the oil and gas industry owing to their high corrosion resistance, specific strength and stiffness. However, CFRP has poor gas barrier performance meaning that a liner has to be inserted. Graphene-based nanomaterials have been demonstrated to improve gas barrier properties in thermoplastic polymers, and thus, a CFRP-graphene hybrid composite could provide an alternative to lined pipes. In this work, a method combining spray coating with vacuum-assisted resin infusion was developed to fabricate CFRP hybrid composites with preferred in-plane aligned graphene nanoplatelets. Tensile and flexural properties, as well as $\mathrm{CO}_{2}$ gas permeability, were evaluated. It was illustrated that both tensile and flexural properties performed better under relatively low GNP loadings $(<0.2 \mathrm{vol} \%)$, while gas barrier property was significantly improved with the increasing GNP loadings which fits the Nielsen model with an effective GNP aspect ratio of 350 .
\end{abstract}

Handling Editor: Stephen Eichhorn.

Address correspondence to E-mail: xudan.yao@manchester.ac.uk

E-mail Address: mark.bissett@manchester.ac.uk 


\section{GRAPHICAL ABSTRACT}

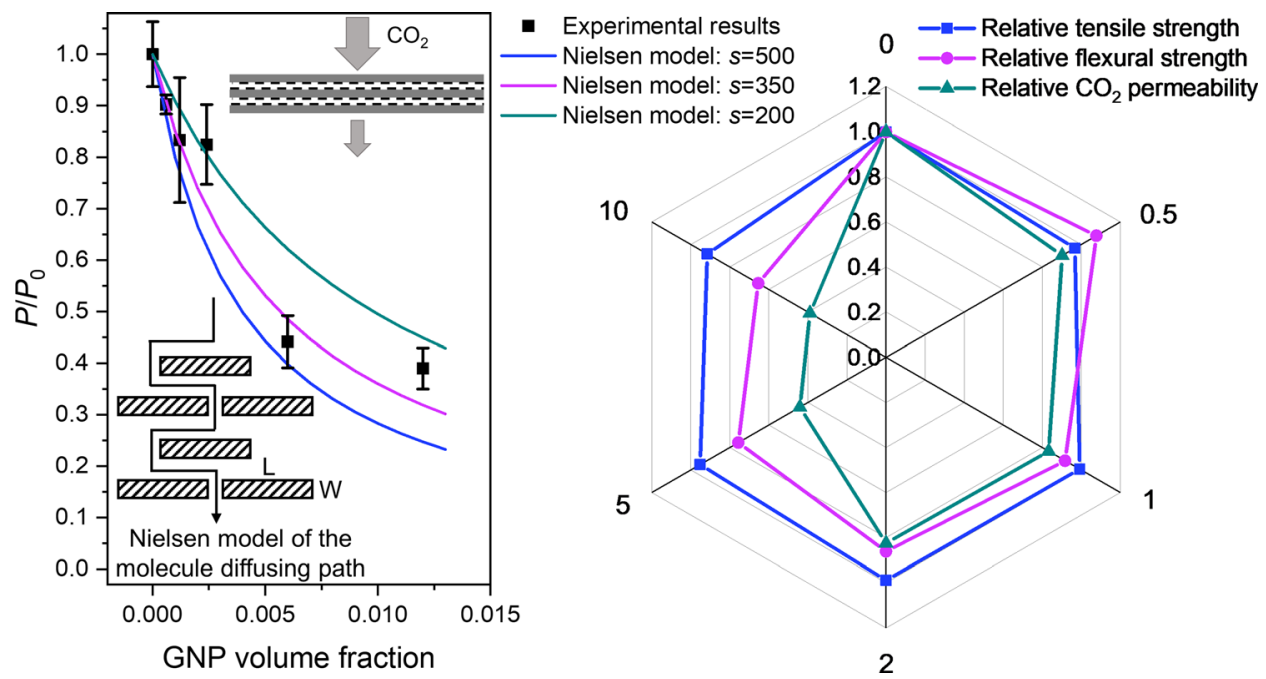

\section{Introduction}

In recent decades, the offshore oil and gas production has moved sharply away from shallow water reserves towards 'deep water' production [1]. However, current steel tether design is unable to work deeper than $1500 \mathrm{~m}$ without a large-size platform that counterbalances high axial tension mechanics. In this case, substituting materials with lightweight are in demand to provide essential savings [2]. As a consequence, for the 'deep water' (up to $1500 \mathrm{~m}$ ) and 'ultra-deep water' (3000 m) offshore exploration and production, non-metallic and lightweight composite materials are needed urgently for easier transport and installation [3].

Carbon-fibre-reinforced polymer (CFRP) composites have been investigated and utilized extensively, with their key advantages including lightweight, high specific strength and stiffness, good corrosion resistance, etc. The superb properties of CFRP composites enable them to be employed for high-end applications, such as aerospace and automotive. After decades of research, the manufacturing technology of CFRP composites has been improved with more economical production, which paves the route for its applications in oil and gas industry [4].
Since monolayer graphene was first isolated in 2004 [5], it has been widely studied due to its exceptional mechanical, electrical and thermal properties. Recently, graphene and its related materials have been widely applied into polymer composites [6-26]; however, scale-up of single- or few-layer graphene remains a challenge. Graphene nanoplatelets (GNPs) are nanoparticles consisting of stacked $2 \mathrm{D}$ graphene which is the most impermeable material [27], with the thickness ranging from $0.34 \mathrm{~nm}$ (i.e. single-layer graphene) to $100 \mathrm{~nm}[19,28,29]$, which can be mass-produced by various techniques (e.g. ball-milling, chemical exfoliation, thermal exfoliation, etc.). The large aspect ratio of GNPs, along with their low cost, facilitates applications in the field as gas barrier materials, which have been studied widely in polymers, such as high-density polyethylene (HDPE) [30], low-density polyethylene (LDPE) [31], polyamide 11 (PA11) [32], polyethylene terephthalate (PET) [33], polypropylene (PP) [34], fluoroelastomer [35] and epoxy [36]. As a result of increasing the tortuosity of gas pathways, significant reductions of gas permeability have been achieved [30-34, 37, 38].

Considering its storage and transportation applications, gas permeability of the CFRP composite has also been investigated. For the well-cured composite, gases could pass through the free volume of the epoxy matrix under diffusion-controlled mechanism, 
driven by the concentration gradient [39-43]. In order to improve the barrier properties, thin-ply [44], $\mathrm{Al}_{2} \mathrm{O}_{3}$ nanoparticles [45], clay-based film [46, 47], aluminium foil [48] and surface coatings [49] have been applied to the CFRP composites. Zhang et al. [36] quantified the effect of GNPs on the gas permeability of epoxy resin and achieved $66 \%$ reduction at the loading of $3 \mathrm{wt} \%$. However, using GNPs to improve the gas barrier properties of CFRP structural composites, which is significant for the non-metallic pipe systems in oil and gas industry, has not yet been reported.

Regarding the composite fabrication, obtaining a uniform GNP dispersion is a key challenge, and diverse techniques have been developed accordingly. Pathak et al. [20] and Prusty et al. [26] initially mixed graphene oxide with epoxy, then utilized a hand layup technique followed by hot pressing to prepare composites. Qin et al. [21] coated carbon fibres (CFs) with GNPs by passing the CFs through a coating solution, then forming a prepreg, and prepared the composites through a hand lay-up and autoclave processing. Chu et al. [50] mixed graphene with resin, then formed the prepreg and cured by autoclave. The composites obtained by either autoclave or hot pressing resulted in a compact structure attributed to the applied pressure, which limited the sample size and shape. Eaton et al. [16] mixed carbon nanofillers with resin, then fabricated the CFRP composites by direct resin infusion, claiming that the resin infusion could be used to make the hybrid composites. Zhang et al. $[23,24]$ investigated the filtration effect of GNPs during resin infusion and found that for small fillers and low fibre volume fractions, large flow length could be achieved before severe filtration started to occur. However, when it comes to large-scale industrial productions, the filtration problem can never be neglected. As an alternative, a spray coating method was proposed and contributed to a better GNP distribution [23, 24].

In order to keep consistent with the current pipe manufacturing processes, such as filament winding and braiding, dry woven fibres were selected in this work. Meanwhile, three different fabrication methods were investigated, including direct vacuum-assisted resin infusion (VARI), wet lay-up and spray coating followed by resin infusion (SCRI). After comparison, the SCRI method was selected and applied to CFRP composites with various GNP loadings, varying from 0 to $10 \mathrm{wt} \%$ relative to carbon fibres. Afterwards, the tensile, flexural and $\mathrm{CO}_{2}$ gas barrier properties of the composites were discussed.

\section{Materials and methods}

\section{Materials}

The GNPs were purchased from XG sciences (USA), with an average particle diameter of $\sim 6.6 \mu \mathrm{m}$ [25], thickness of $6-8 \mathrm{~nm}(\sim 20$ layers of graphene $)$ and density $\left(\rho_{\mathrm{g}}\right)$ of $2.2 \mathrm{~g} \mathrm{~cm}^{-3}$. Plain weave carbon fibre was purchased from Sigmatex (UK), which used Hexcel (USA) HexTow ${ }^{\circledR}$ carbon fibre, with a density of $199 \mathrm{~g} \mathrm{~m}^{-2}$. Araldite epoxy resin and Aradur hardener from Huntsman (USA) were used as the low viscosity epoxy resin and hardener. Acetone was supplied by Fisher Scientific (UK).

\section{Sample preparation}

Eight layers of the plain weave carbon fibre with a quasi-isotropic lay-up $([0 / 90] /[ \pm 45])_{2 s}$ were selected for mechanical testing sample preparation. Considering the thickness limitation of the testing rig for gas permeability, composites with three layers of the carbon fibre ([0/90]/[ \pm 45$] /[0 / 90])$ were prepared as well. For both direct VARI and wet lay-up methods, GNPs were initially dispersed in the resin by a highspeed vacuum mixer (Fig. S1), followed with adding the hardener for further mixing, with mixing conditions shown in Table S1. For the spray coating method, a Paasche VL airbrush system connected with an Iwata Power Jet Lite compressor was employed. GNPs were dispersed in pure acetone, at the concentration of $\sim 5 \mathrm{mg} \mathrm{mL}^{-1}$, through ultrasonication for $40 \mathrm{~min}$, afterwards, the mixed solution was sprayed onto the internal surfaces of the plain weave carbon fibres, as shown in Fig. 1 . Then, the

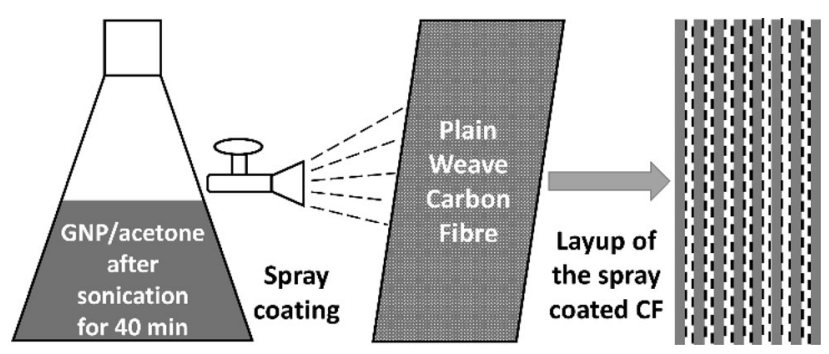

Figure 1 Schematic of the spray coating process. All internal surfaces of the carbon fibres were coated with GNPs. 
carbon fibres were left overnight to allow the acetone to evaporate completely. Carbon fibres were weighted before and after the spray coating to evaluate the amount of GNPs coated onto the fibres. Subsequently, the composites were fabricated through layup and resin infusion.

The direct VARI method resulted in a severe filtration effect, in which a large fraction of GNPs were filtered and stayed in the infusion mesh, rather than being distributed throughout the carbon fibre composites (Fig. S1). Regarding composites made with the wet lay-up method, visible voids were observed in the cross-section analysis (Fig. S3). Details of these two methods can be found in the Supplementary Information. In comparison, composites fabricated through the SCRI method tend to achieve in-plane aligned GNP distribution (Fig. 1) and no visible voids, this method was therefore used for further studies in this work. CFRP hybrid composites with carbon fibres spray coated by $0-10 \mathrm{wt} \%$ (relative to the carbon fibre) GNPs were prepared, with $0 \mathrm{wt} \%$ GNP representing the control sample.

\section{Characterization}

Transmission electron microscopy (TEM) bright field images and diffraction patterns were obtained for the GNPs, using a FEI Tecnai G2 20 ( $\left.\mathrm{LaB}_{6}\right)$. Raman spectroscopy of the GNP was obtained by a Renishaw InVia Raman system equipped with a $633 \mathrm{~nm}$ laser. A TESCAN MIRA3 SC Scanning Electron Microscope (SEM) was used to observe the morphology of CFs, GNPs and fracture surfaces of the composites.

\section{Mechanical testing}

Mechanical properties of the composites, including tensile and four-point flexural properties, were evaluated based on the standards of ASTM D3039 and ASTM D7264, respectively, each test with three specimens. For the tensile tests, the specimen size was selected at $250 \mathrm{~mm} \times 25 \mathrm{~mm} \times 2 \mathrm{~mm}$ following the recommendation from the standard, and the tests were undertaken with constant temperature of $23^{\circ} \mathrm{C}$ and relative humidity of $50 \%$. A video extensometer was employed to monitor the extension, with the gauge length calibrated at $50 \mathrm{~mm}$, and a testing rate of $2 \mathrm{~mm} \mathrm{~min}^{-1}$.
Based on the instructions from the standard, the specimen size of $100 \mathrm{~mm} \times 12.7 \mathrm{~mm} \times 2 \mathrm{~mm}$ was selected for the flexural testing, with the support span and load span set at $67.2 \mathrm{~mm}$ and $33.6 \mathrm{~mm}$, respectively. Afterwards, the testing rate $(Y$, $3.59 \mathrm{~mm} / \mathrm{min}$ ) was calculated based on Eq. 1 from the ASTM D6272:

$Y=0.167 Z L^{2} / d$

where $L$ is the support span $(\mathrm{mm}), d$ is the depth (thickness) of beam $(\mathrm{mm})$, and $\mathrm{Z}$ is the straining rate of the outer fibres $(0.01 \mathrm{~mm} / \mathrm{mm} \mathrm{min})$.

\section{Gas permeability testing}

In order to evaluate the gas barrier performance of CFRP/GNP hybrid composites, the gas permeability was measured based on the standard BS ISO 15105-1:2007. Carbon dioxide $\left(\mathrm{CO}_{2}\right)$ was used as a model gas and a differential pressure testing system (Fig. 2) was used to characterize each of the samples. The testing specimen was cut from the composite panel into a circular sample with a diameter at $29.5 \mathrm{~mm}$ (Fig. 2) and tested for $24 \mathrm{~h}$.

Before starting the measurement, the testing system was evacuated to $10^{-3} \mathrm{mbar}$, then all valves were closed except number 1 which was opened, allowing the gas to flow from the high-pressure (HP) cylinder to the chamber with a fixed volume of $500 \mathrm{~mL}$. Once the chamber was filled, valve 1 was closed, then valve

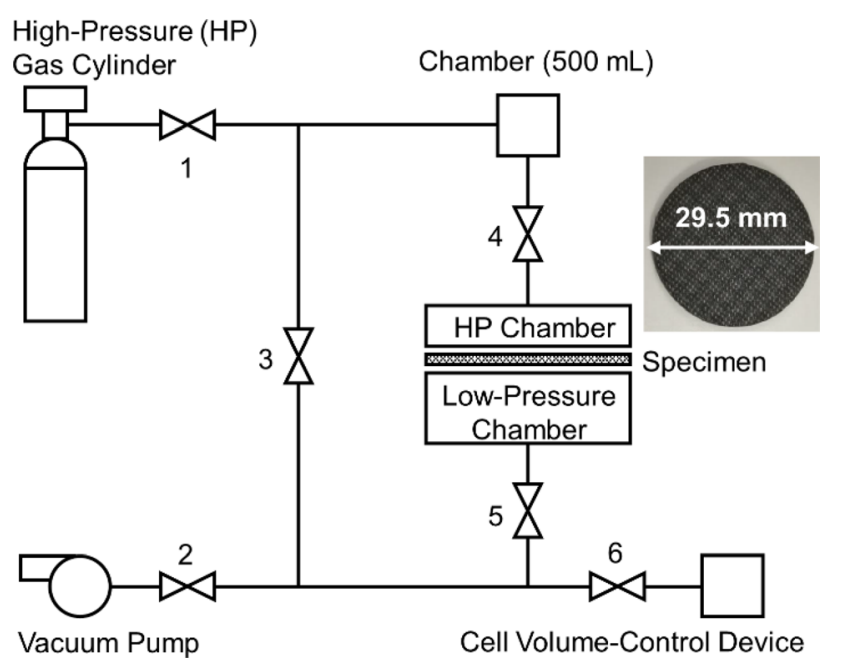

Figure 2 Schematic of the $\mathrm{CO}_{2}$ gas permeability testing setup in which number 1-6 represent valves, with a photograph of a representative sample. 
4 was opened and pressure change in the low-pressure chamber was monitored as a function of time.

The gas permeability $(P)$ was determined based from the following equation:

$P=\frac{V_{\mathrm{c}}}{R \times T \times p_{\mathrm{h}} \times A} \times \frac{\mathrm{d} p}{\mathrm{~d} t} \times d$

where $V_{\mathrm{c}}$ is the volume of the low-pressure chamber, $R$ is the gas constant $\left(8.31 \mathrm{~J} \cdot \mathrm{mol}^{-1} \cdot \mathrm{K}^{-1}\right), T$ is the temperature, $p_{\mathrm{h}}$ is the pressure of the high-pressure chamber (1320 mbar), $A$ is the transmission area of the specimen, $d p / d t$ is the change in pressure per unit time of the low-pressure chamber, $d$ is the thickness of the specimen.

\section{Results and discussion}

\section{GNP characterization and distribution}

The as-received GNPs were characterized by Raman spectroscopy and TEM for their morphology, crystal and electronic structures, as shown in Fig. 3. The Raman spectrum of the GNP (Fig. 3a) shows welldefined $G, 2 D$ and $D$ bands for graphitic materials, with peaks at around $1580 \mathrm{~cm}^{-1}, 2680 \mathrm{~cm}^{-1}$ and $1350 \mathrm{~cm}^{-1}$. The intense $G$ band is the signature Raman band of the $\mathrm{C}-\mathrm{C} \mathrm{sp^{2 }}$ network of the graphene plane [51]. The 2D band is broad and asymmetric suggesting that the nanoplatelets consist of many layers of graphene [51, 52]. The broad and weak $D$ band indicates the structural defects present in the structure, which is related to the zone-boundary phonons [52]. The TEM bright field images (Fig. 3b, c) illustrate the GNP lateral size sits in the micron level. The corresponding selected area electron diffraction (SAED) patterns (Fig. 3d, e), from the GNPs in Fig. 3b, c, demonstrate that the GNPs have highly ordered structures consisting of hexagonal arrangements of carbon atoms, which highlights their crystallinity [53].

For the spray coating process, the weight percentage of the GNPs was determined based on the weight of carbon fibres. In order to evaluate the spray coating efficiency, carbon fibres were weighed before and after the spray coating process. Losses due to overspray and other mechanisms of $\sim 70 \%$ of the GNP mass resulted in a coating efficiency of $\sim 30 \%$. After spray coating with different loadings of GNPs, the carbon fibres were characterized by SEM, as shown in Fig. 4. It appeared that with increasing loadings, the coated GNPs tend to form a densely arranged continuous network, which is considered to be beneficial to gas hindrance. The final GNP weight fractions $\left(W_{\mathrm{g}}\right)$ of cured composites were evaluated based on treating the whole CFRP control composites as the matrix, with the density $\left(\rho_{\mathrm{m}}\right)$ at $1.43 \mathrm{~g} \mathrm{~cm}^{-3}$ and $1.47 \mathrm{~g} \mathrm{~cm}^{-3}$ for $8 \mathrm{~L}$ and $3 \mathrm{~L}$ composites, respectively. Afterwards, the GNP volume fraction $\left(V_{\mathrm{g}}\right)$ can be obtained by: (a)

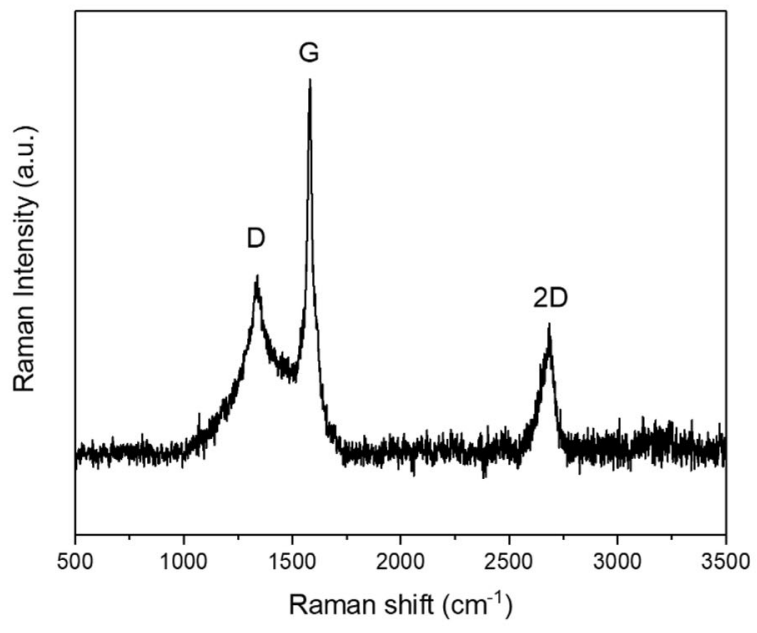

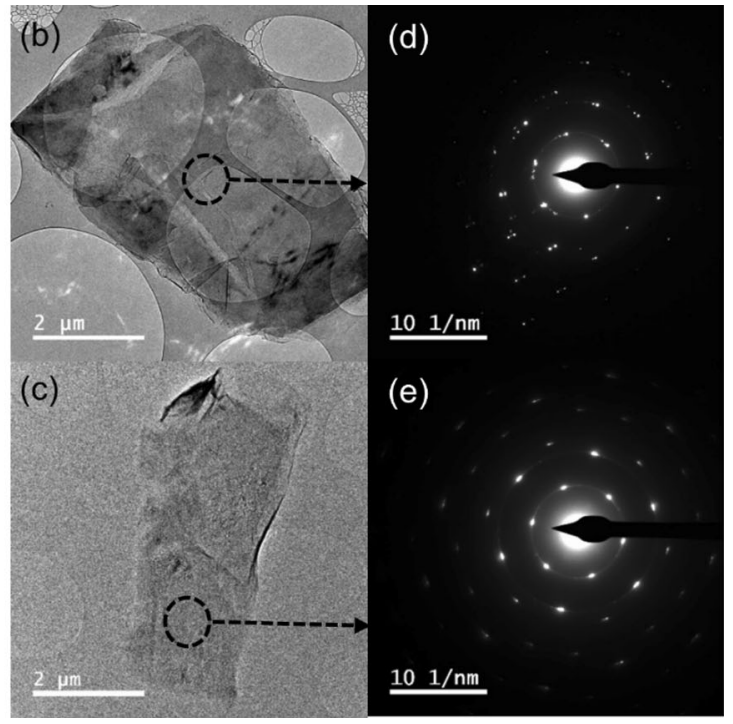

Figure 3 Raman spectrum (a), TEM bright field images $(\mathbf{b}, \mathbf{c})$ and corresponding selected area electron diffraction patterns $(\mathbf{d}$, e) of the GNPs. 

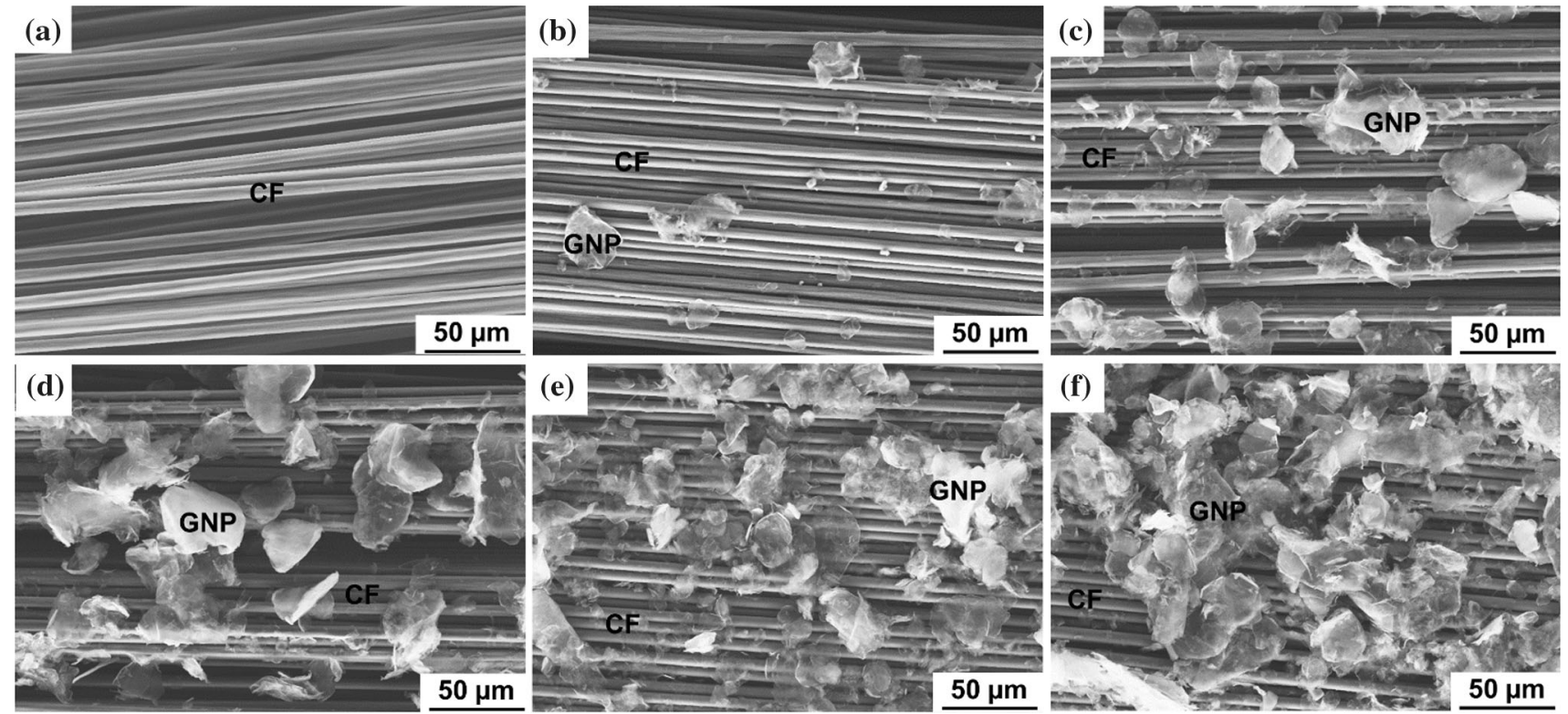

Figure 4 SEM images of carbon fibres spray coated with (a-f) $0,0.5,1,2,5$ and 10 wt $\%$ GNPs.

$W_{\mathrm{g}}=\frac{\rho_{\mathrm{g}} V_{\mathrm{g}}}{\rho_{\mathrm{g}} V_{\mathrm{g}}+\rho_{\mathrm{m}}\left(1-V_{\mathrm{g}}\right)}$

The carbon fibre volume fractions, along with the final GNP weight and volume fractions of cured composites, are summarized in Tables 1 and 2 for the eight- and three-layer composites, respectively.

\section{Effect of GNP loading on mechanical properties}

\section{Tensile properties}

Figure 5a shows the representative tensile stressstrain curves of the composites with different GNP loadings, embedded with their fracture images. Composites filled with GNPs up to 0.52 vol\% showed linear behaviour through the whole tensile procedure, with the tensile strength (normalized by the fibre volume fraction, see Fig. S4) remained unchanged within error (Fig. 5b). The tensile moduli of the samples were determined from the linear curves using the strain range between 0.1 and $0.3 \%$, which were also normalized by the fibre volume fraction. With increasing GNP loadings, the tensile modulus which represents the elastic properties, presented no obvious change and the values sit within error bars (Fig. 5b). Truong et al. [54] also reported similar behaviour, namely adding GNPs did not affect the tensile strength of the CFRP composites, as the dominant load-bearing component during the tensile procedure is the carbon fibres themselves [22]. However, composites with 1.05 vol\% GNPs performed nonlinearly when the tensile strain increased up to $0.8 \%$, i.e. near the final fracture (Fig. 5a). This nonlinearity was caused by the delamination prior failure [7, 15], due to the densely arranged continuous GNP network (Fig. 6e) hindered the stress

Table 1 Carbon fibre (CF) volume fraction, GNP weight and volume fractions of cured eight-layer composites

\begin{tabular}{llll}
\hline Sample no. & CF volume fraction, Vf $($ vol \%) & GNP weight fraction, $W_{\mathrm{g}}(\mathrm{wt} \%)$ & Final GNP volume fraction, $V_{\mathrm{g}}(\mathrm{vol} \%)$ \\
\hline 1 & 42.07 & 0 & 0 \\
2 & 41.72 & 0.08 & 0.05 \\
3 & 41.51 & 0.16 & 0.10 \\
4 & 41.90 & 0.32 & 0.21 \\
5 & 41.23 & 0.80 & 0.52 \\
6 & 41.05 & 1.61 & 1.05 \\
\hline
\end{tabular}


Table 2 Carbon fibre (CF) volume fraction, GNP weight and volume fractions of cured three-layer composites

\begin{tabular}{llll}
\hline Sample no. & CF volume fraction, Vf (vol\%) & GNP weight fraction, $W_{\mathrm{g}}(\mathrm{wt} \%)$ & Final GNP volume fraction, $V_{\mathrm{g}}(\mathrm{vol} \%)$ \\
\hline 1 & 43.49 & 0 & 0 \\
2 & 43.49 & 0.09 & 0.06 \\
3 & 43.35 & 0.18 & 0.12 \\
4 & 43.28 & 0.36 & 0.24 \\
5 & 43.21 & 0.89 & 0.60 \\
6 & 42.60 & 1.79 & 1.20 \\
\hline
\end{tabular}
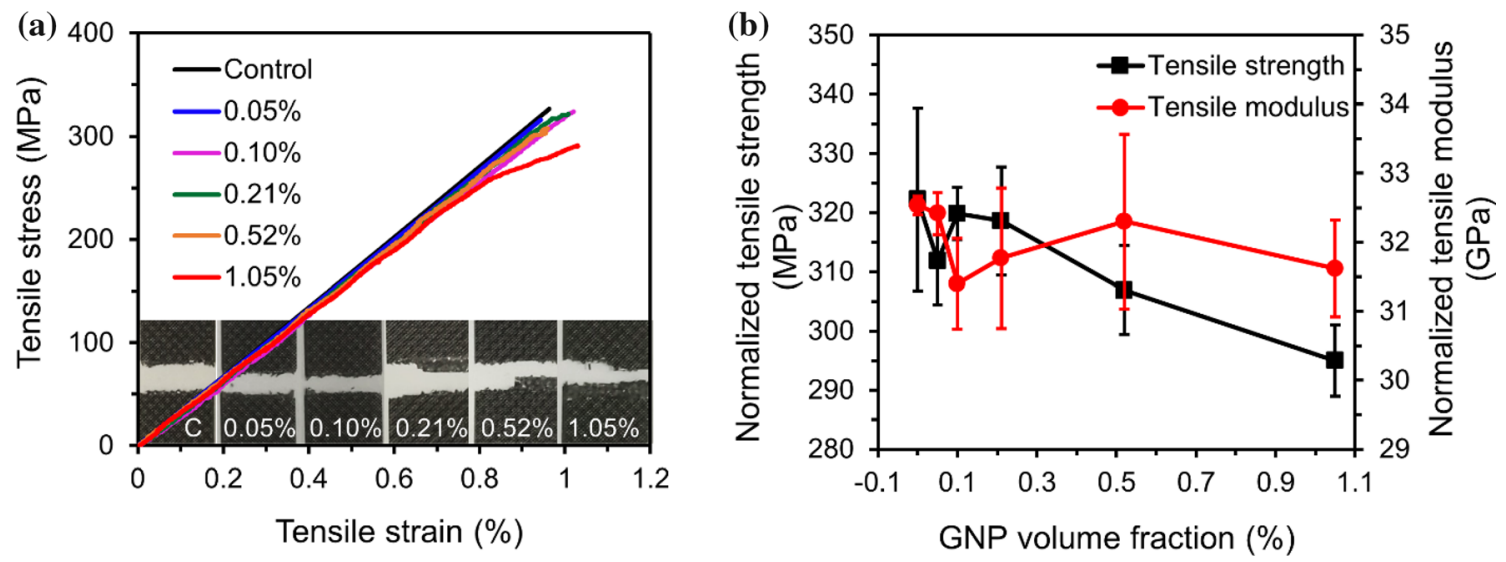

Figure 5 a Representative stress-strain curves of the composites under tension, embedded with the fracture images. b Normalized tensile strength and modulus of the composites.

transfer across the thickness direction, which also led to $8.5 \%$ (Fig. 5b, Table S2) decrease in the tensile strength.

SEM micrographs (Fig. 6a-f) of the fracture surfaces illustrate that the control composites failed with the fibre breakage and fibre pull out, resulted with a lateral mode (Fig. 5a); similar to the $0.10 \%$ composites which have partial carbon fibre surfaces coated with GNPs and retained part of the original interfacial connections. While for the 1.05 vol. \% sample, carbon fibres were fully covered by the continuous GNP network, polymeric chains were unable to penetrate through the graphene layers, extensive delamination occurred prior to the final failure, as a result, fracture failed with an angled surface (Fig. 5a).

\section{Flexural properties}

The tensile properties of the composites mainly depend on the reinforcing carbon fibres, whereas the flexural performance is typically governed by a combination of the fibres, the matrix and their corresponding interfacial interactions. Figure 7a shows the flexural stress-strain curves for all the composites under four-point bending. Initially, the stresses of all samples increased linearly with the strains, indicating the elastic deformation. Samples filled with GNPs up to $0.10 \mathrm{vol} \%$ failed elastically at around $1.2 \%$ strain. However, with respect to composites with higher GNP loadings ( $>0.21 \mathrm{vol} \%$ ), delamination emerged prior to reaching the ultimate flexural stresses of the materials. As a result, with the GNP loading increasing, both flexural strength and modulus (calculated from the strain ranging from 0.1 to $0.3 \%$ ) increased at first followed by a continuous decrease with the inflection point at $0.05 \mathrm{vol} \%$, where increased by $7.8 \%$ and $4.3 \%$, respectively (Fig. $7 \mathrm{~b}$, Table S3). Kamar et al. [7], Kwon et al. [14], Pathak et al. [20] and Prusty et al. [26] also reported similar behaviours. As low loadings of GNPs are beneficial to mechanical anchoring and interlocking between the carbon fibres and epoxy resin under the bending load, which contributed to improve the flexural properties [20,55]. However, as the loading further increasing, more and more GNPs formed a 'densely packed layer' (Figs. 4, 6e, 8e) which could internally 
Figure 6 SEM images of tensile fracture surfaces for (a, b) control, (c, d) $0.10 \%$ and (e, f) $1.05 \%$ composites.
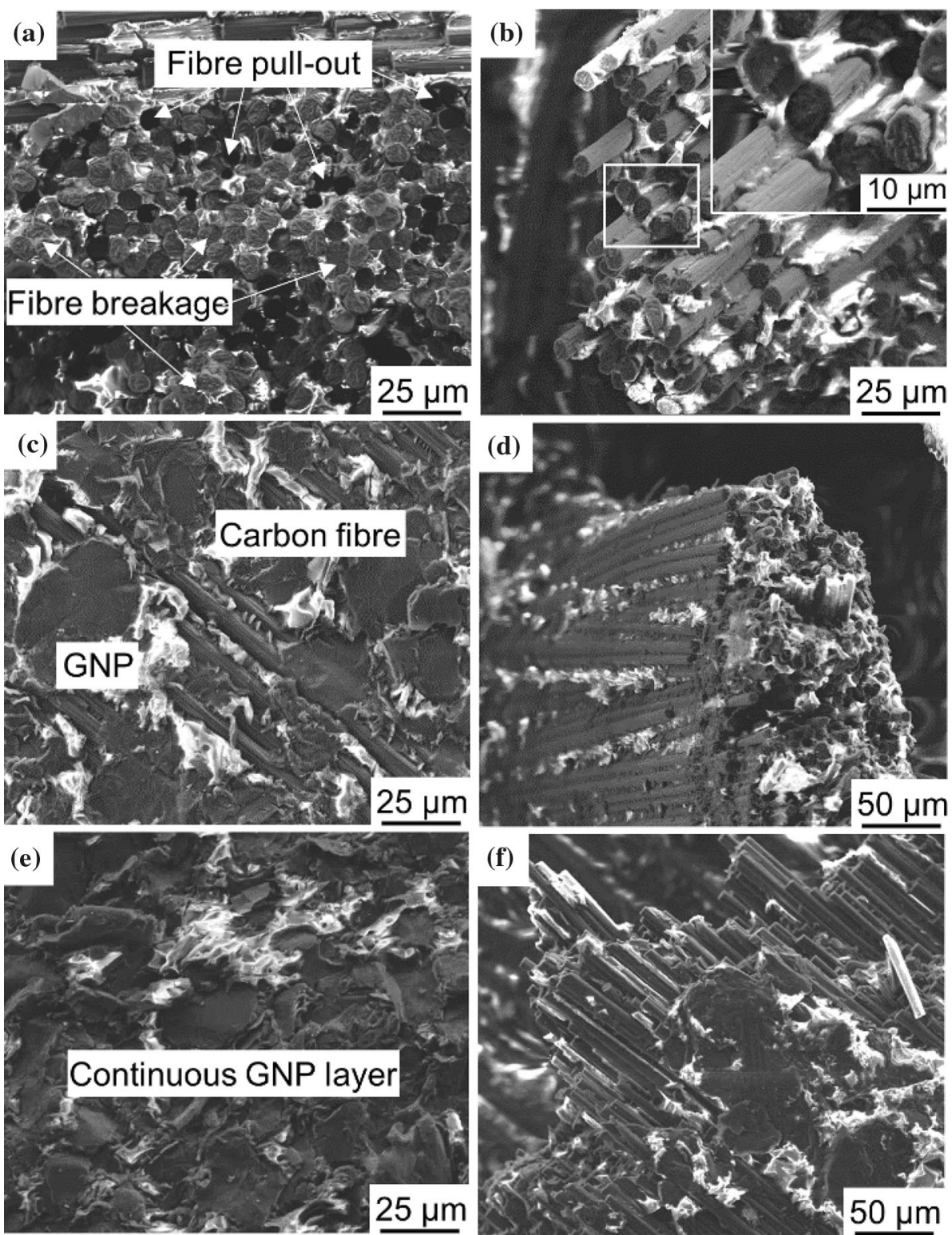

delaminate, accelerating the delamination during the bending procedure, and resulted in lower flexural strength $[7,15]$.

\section{Effect of GNP loading on gas permeability}

Impermeability to gas is one of the key factors for CFRP to be used in the petrochemicals industry. Therefore, we have characterized the $\mathrm{CO}_{2}$ permeability in the present work for the hybrid composite materials prepared, as shown in Fig. 8a for the measured pressure against time and Fig. $8 \mathrm{~b}$ calculated permeability of the materials. It is demonstrated that the $\mathrm{CO}_{2}$ permeability of the materials was reduced significantly (55.8\%, Table S2) with the increasing GNP loadings up to only $0.6 \mathrm{vol} \%$, indicating that the GNPs, owing to their 2D geometry, can efficiently hinder gas migration through the composite structure. The mechanism underpinning the reduction of the gas permeability is considered to be the increased tortuosity of the pathways of the gas molecules being extended by the GNPs [56], as suggested by the microstructure shown in Fig. $8 \mathrm{c}-\mathrm{e}$.

In comparison, dispersed $\mathrm{Al}_{2} \mathrm{O}_{3}$ nanoparticles, as a OD material, did not improve the gas barrier properties for the composite laminates [45]. In order to improve the tolerance against damage and leakage of the CFRP laminates, interleaving has been widely 


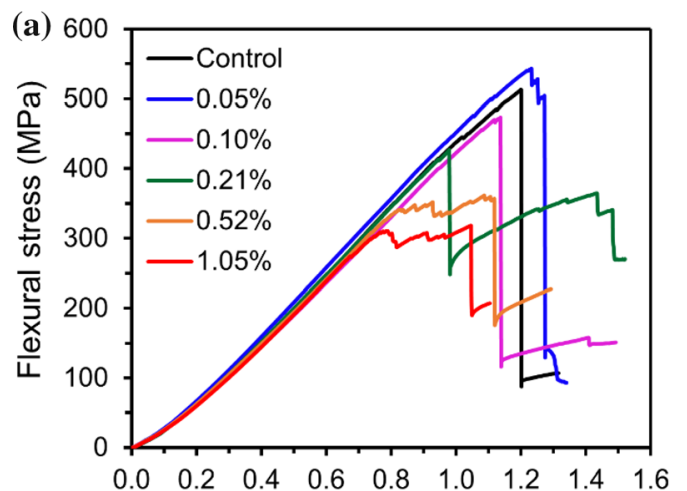

Flexural strain $(\%)$

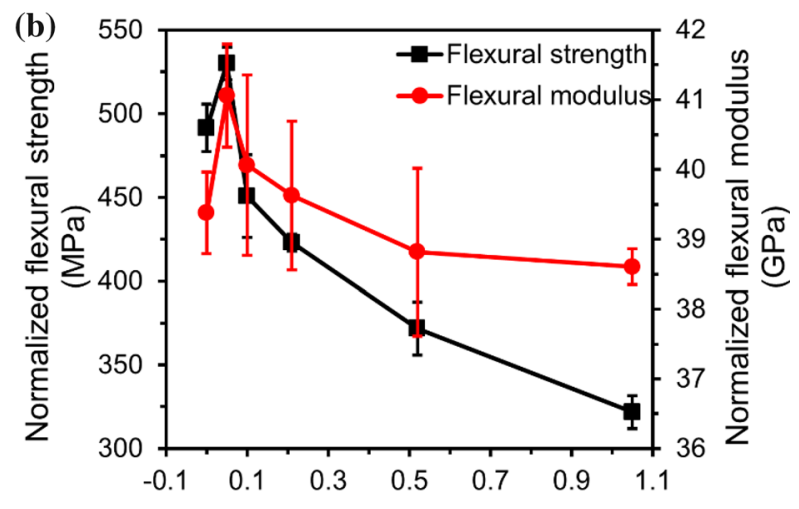

GNP volume fraction (\%)

Figure 7 a Stress-strain curves of the CFRP composites with different GNP loadings under four-point bending. $\mathbf{b}$ Normalized flexural strength and modulus of the composites.
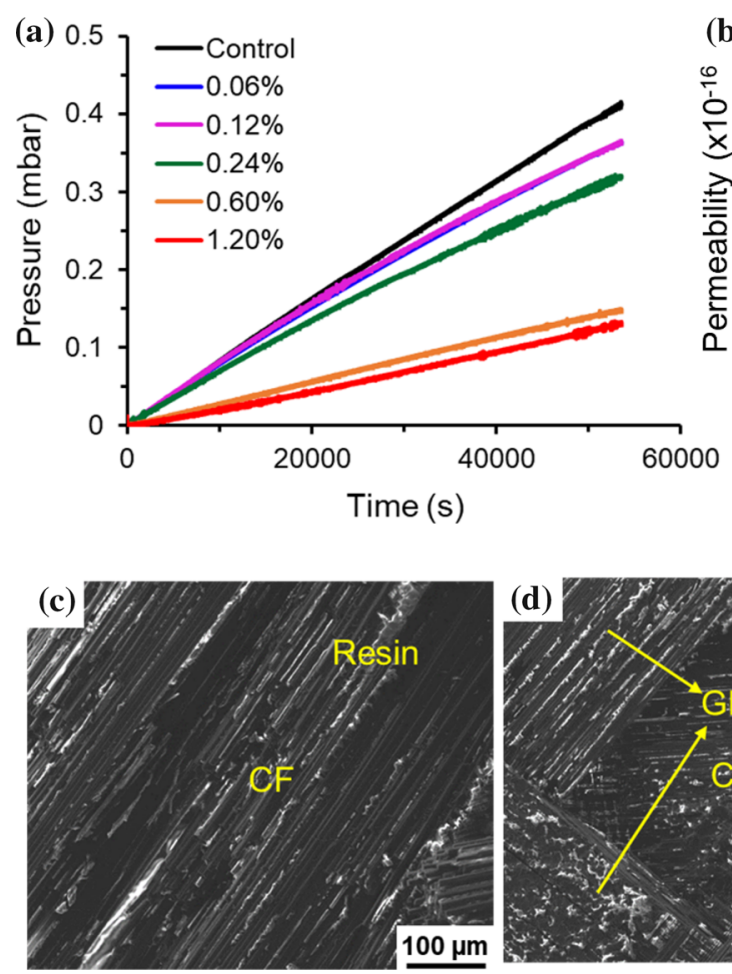
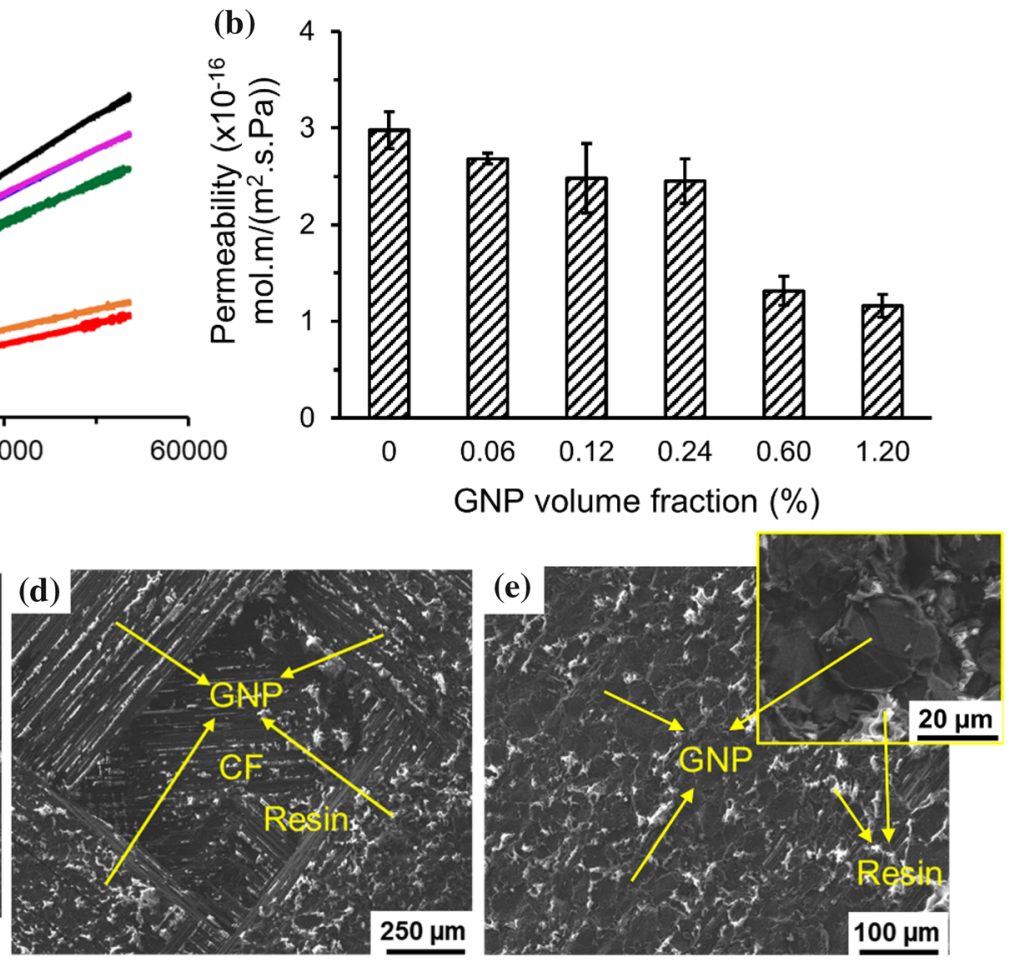

Figure 8 a Downstream pressure change against time and $\mathbf{b} \mathrm{CO}_{2}$ permeability of samples with six different GNP loadings. SEM images of interfaces for composites with GNP volume fractions of c $0, \mathbf{d} 0.06 \mathrm{vol} \%$ and e $1.20 \mathrm{vol} \%$.

applied with barrier layers such as aluminium foil, aluminized Mylar, $\beta$-titanium [48] and thin-ply prepregs [44], as well as surface coatings [49]. Ebina et al. interleaved a dense and highly oriented clay crystal film into the CFRP composites, and the gas (hydrogen) barrier properties were improved by two orders of magnitude [46, 47]. As a result of the large aspect ratio and superior gas barrier properties of the GNP, it was applied into epoxy resin and achieved 83\% (helium, [57]) and 66\% $\left(\mathrm{CO}_{2}\right.$, [36]) permeability reduction at the loading of $2 \mathrm{wt} \%$ and $3 \mathrm{wt} \%$, which is consistent with the results achieved in this work when applied GNPs into CFRP composites.

Here, we analyse our results using the Nielsen model (Eq. 4) that is used to describe the minimum permeability of gases for platelets-filled polymers (Fig. 9). The permeability of the hybrid composites 


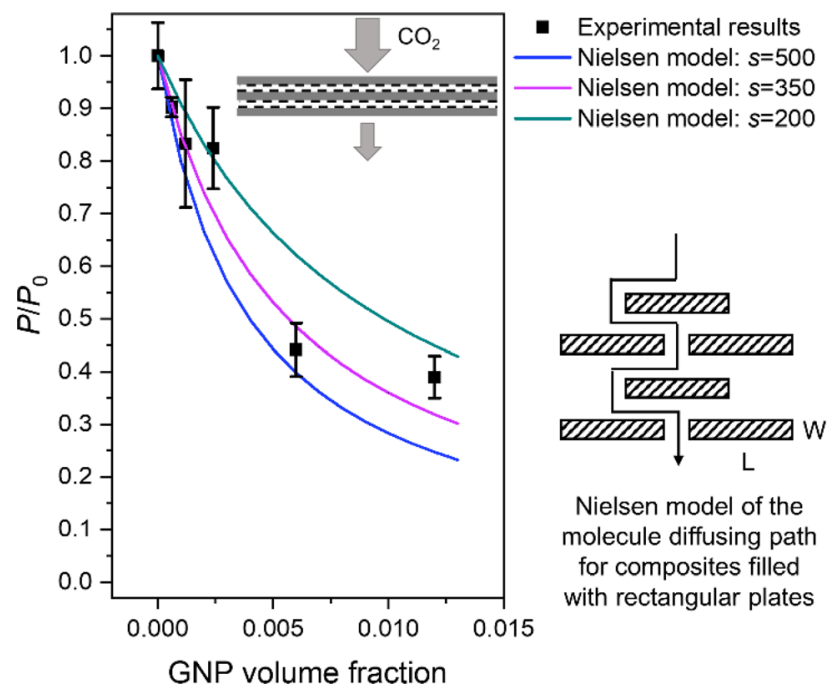

Figure 9 Relative $\mathrm{CO}_{2}$ permeability of the composites $\left(P / P_{0}\right)$ against the volume fraction of GNPs $\left(V_{\mathrm{g}}\right)$ and corresponding fitted curves of the Nielsen model ( $s$ represents the effective aspect ratio of the GNP). Nielsen model of the molecule diffusing path [58] for composites filled with rectangular plates is inset.

$(P)$ with a volume fraction of GNPs $\left(V_{\mathrm{g}}\right)$ is given by $[36,58]$ :

$P=\frac{1-V_{\mathrm{g}}}{1+s V_{\mathrm{g}} / 2} P_{0}$

where $P_{0}$ is the gas permeability of the sample with only carbon fibres, $V_{\mathrm{g}}$ is the volume fraction of the GNPs to the composites and $s$ is the effective aspect ratio (lateral size/thickness) of the GNP, which represents the aspect ratio contributing to the gas permeation hindrance.

The experimental results were fitted with the Nielson model, as shown in Fig. 9. The resulting relative $\mathrm{CO}_{2}$ permeability of the composites $\left(P / P_{0}\right)$, as a function of GNP volume fraction, is bounded by two Nielsen fitted curves with the effective aspect ratio (s) of 200 and 500. After taking the median $(s=$ $350)$, the results fitted very well with the Nielsen model. The reason why the effective aspect ratio of the GNP is smaller than the given data $(\sim 1000$, $6.6 \mu \mathrm{m} / 6-8 \mathrm{~nm}$ ) could be attributed to the size degradation and nanoplatelets overlaps during the sample preparation procedure, which is consistent with our previous studies [59]. Different from conventional methods, such as mixing of the nanofillers into epoxy prior to the composite fabrication $[16,20,26]$, with the spray coating of the GNPs, we ended up introducing 'impenetrable' layers of the inplane tentatively highly aligned GNPs between the plies, which enabled the GNPs to maximize path lengths of the gas. Thus, the composites obtained fit the application conditions of the Nielson model which demonstrating the minimum gas permeability. Details of the validity of Nielsen's model can be found in the Supplementary Information.

\section{Discussion}

The relative mechanical and barrier properties of the hybrid composites are summarized in Fig. 10. In addition, the detailed tensile and flexural strength and modulus, along with the gas $\left(\mathrm{CO}_{2}\right)$ permeability data, are summarized in Tables S2 and S3. The result indicates that with the increasing GNP loading, the tensile strength, which was dominated by the reinforced carbon fibres, remained unchanged with slight scattering; the flexural strength increased at first followed with a continuous decrease, due to the delamination before the ultimate flexural strength achieved, while the $\mathrm{CO}_{2}$ permeability decreased continuously which fits the Nielsen model very well.

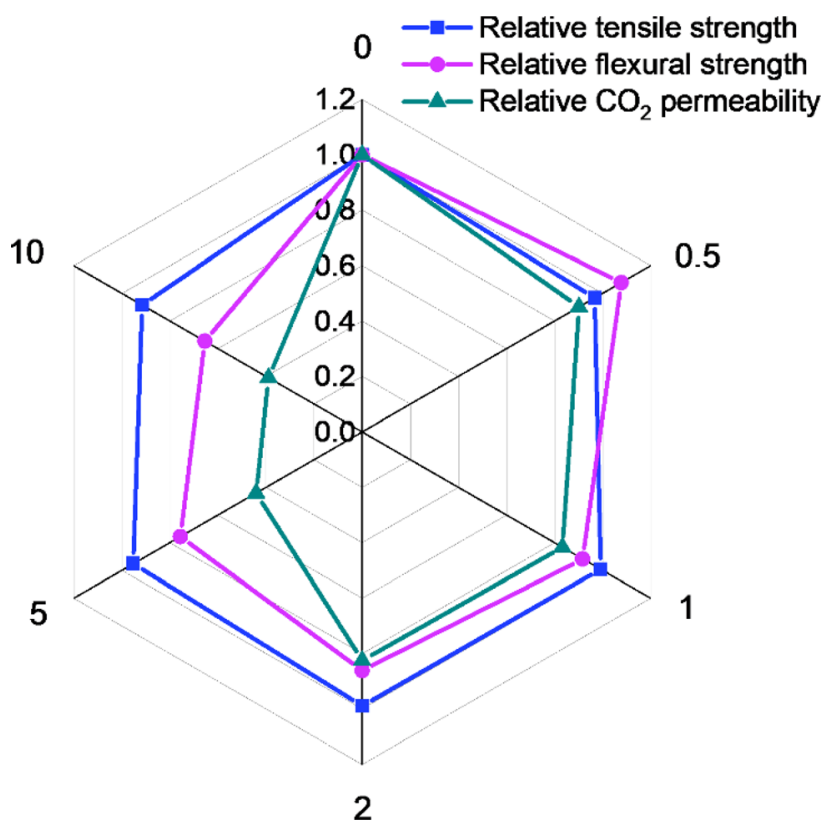

Figure 10 Relative tensile and flexural strength and $\mathrm{CO}_{2}$ permeability of the composites with the six different GNP loadings (wt $\%$ relative to $\mathrm{CFs}$ ). 


\section{Conclusions}

This work highlights a flexible hybrid nanocomposite fabrication process, spray coating followed with vacuum-assisted resin infusion, which is promising for uniform and large-scale production of hybrid composites. The proposed technique in this work can be introduced to any type of fibres, including woven fibres and unidirectional fibres, without altering their patterns.

As the tensile property of the CFRP composites mainly depends on the carbon fibres, no significant change was observed upon the addition of graphene nanoplatelets up to $0.52 \mathrm{vol} \%$. While flexural properties depend on fibres, matrix and interfacial properties, with increasing the GNP loading, both flexural strength and modulus increased at first then decreased with the inflection point at $0.05 \mathrm{vol} \%$, where increased by $7.8 \%$ and $4.3 \%$, respectively. The high degree of in-plane alignment tendency of the GNPs achieved through spray coating, combined with their 2D geometry, led to significant improvements on $\mathrm{CO}_{2}$ gas barrier properties with increasing the GNP loading. In particular, for 0.6 vol $\%$ and 1.2 vol\% composites, the $\mathrm{CO}_{2}$ permeability at the pressure of $1.3 \mathrm{~atm}$, decreased by $56 \%$ and $61 \%$, respectively, relative to the pure CRFP. The gas permeability of the hybrid composites with different loadings of GNPs was examined by the Nielsen model, indicating that an average aspect ratio of the GNPs of 350 can be considered to be effective for the gas permeability reduction.

Combining spray coating with resin infusion enables us to optimize the consumption of GNPs with desired properties. In general, low loadings $(<0.2 \mathrm{vol} \%)$ of GNPs benefit mechanical improvement, while high loadings ( $>0.6 \mathrm{vol} \%$ ) hinder gas permeation significantly. Considering the overall performance, the percolation threshold for the gas permeability appears between 0.2 and $0.6 \mathrm{vol} \%$ as shown in Fig. 9, which we would suggest as the optimal loading range of GNPs, where gas barrier properties improved by $17.5-55.8 \%$. In this range, flexural strength decreased by $13.9-24.3 \%$, while the tensile strength and modulus as well as flexural modulus presented no obvious change. When flexural properties are critically important, GNP loading of 0.05 vol. $\%$ is preferable with the strength and modulus increased by $7.8 \%$ and $4.3 \%$, respectively, and $\mathrm{CO}_{2}$ barrier properties increased by $9.8 \%$. With the addition of an appropriate amount of GNPs into the CFRP system, the mechanical and gas barrier properties could be tuned effectively. Compared with dispersing GNPs in the resin, such technique can make full use of GNPs to maximize the efficiency of improving gas barrier properties, thus save the usage of GNPs. Furthermore, the technique is easy to scale and could be adopted to other 2D fillers, such as functionalized GNPs with applications in the oil and gas industry.

\section{Acknowledgements}

This work was funded by PETRONAS in collaboration with the University of Manchester. We also acknowledge EP/K016946/1 and Dr. Andrew Wallwork for the development of the gas permeation rig. All research data supporting this publication are directly available within this publication and the corresponding Supporting Information, as well as available from the corresponding authors upon reasonable request.

\section{Declarations}

Conflict of interest The authors have no conflicts of interest related to this work.

Supplementary Information: The online version contains supplementary material available at http s:/ /doi.org/10.1007/s10853-021-06467-z.

Open Access This article is licensed under a Creative Commons Attribution 4.0 International License, which permits use, sharing, adaptation, distribution and reproduction in any medium or format, as long as you give appropriate credit to the original author(s) and the source, provide a link to the Creative Commons licence, and indicate if changes were made. The images or other third party material in this article are included in the article's Creative Commons licence, unless indicated otherwise in a credit line to the material. If material is not included in the article's Creative Commons licence and your intended use is not permitted by statutory regulation or exceeds the permitted use, you will need to obtain permission directly from the copyright holder. To view a copy of this licence, visit http://creativecommons.org/licen ses/by $/ 4.0 /$. 


\section{References}

[1] Hale JM, Shaw BA, Speake SD, Gibson AG (2000) High temperature failure envelopes for thermosetting composite pipes in water. Plast Rubber Compos Process Appl 29(10):539-548. https://doi.org/10.1179/146580100101540 752

[2] Ochoa OO, Salama MM (2005) Offshore composites: transition barriers to an enabling technology. Compos Sci Technol 65:2588-2596. https://doi.org/10.1016/j.compscitec h.2005.05.019

[3] Gibson AG, Linden JM, Elder D, Leong KH (2011) Nonmetallic pipe systems for use in oil and gas. Plast Rubber Compos 40(10):465-480. https://doi.org/10.1179/17432898 11 Y.0000000006

[4] Taheri F (2013) Advanced fiber-reinforced polymer (FRP) composites for the manufacture and rehabilitation of pipes and tanks in the oil and gas industry. Advanced Fibre-Reinforced Polymer (FRP) Composites for Structural Applications. 662-704. https://doi.org/10.1533/9780857098641.4. 662

[5] Novoselov KS, Geim AK, Morozov SV, Jiang D, Zhang Y, Dubonos SV et al (2004) Electric field effect in atomically thin carbon films. Science 306(5696):666-696. https://doi. org/10.1126/science.1102896

[6] Jiang J, Yao X, Xu C, Su Y, Zhou L, Deng C (2017) Influence of electrochemical oxidation of carbon fiber on the mechanical properties of carbon fiber/graphene oxide/epoxy composites. Compos Part A Appl Sci Manuf 95:248-256. h ttps://doi.org/10.1016/j.compositesa.2017.02.004

[7] Kamar NT, Hossain MM, Khomenko A, Haq M, Drzal LT, Loos A (2015) Interlaminar reinforcement of glass fiber/ epoxy composites with graphene nanoplatelets. Compos Part A Appl Sci Manuf 70:82-92. https://doi.org/10.1016/j.com positesa.2014.12.010

[8] Yao X, Gao X, Jiang J, Xu C, Deng C, Wang J (2018) Comparison of carbon nanotubes and graphene oxide coated carbon fiber for improving the interfacial properties of carbon fiber/epoxy composites. Compos Part B Eng 132:170-177. https://doi.org/10.1016/j.compositesb.2017.09 .012

[9] Gao B, Zhang R, He M, Sun L, Wang C, Liu L et al (2016) Effect of a multiscale reinforcement by carbon fiber surface treatment with graphene oxide/carbon nanotubes on the mechanical properties of reinforced carbon/carbon composites. Compos Part A Appl Sci Manuf 90:433-440. https://d oi.org/10.1016/j.compositesa.2016.08.012

[10] Wang C, Li J, Sun S, Li X, Zhao F, Jiang B et al (2016) Electrophoretic deposition of graphene oxide on continuous carbon fibers for reinforcement of both tensile and interfacial strength. Compos Sci Technol 135:46-53. https://doi.org/10. 1016/j.compscitech.2016.07.009

[11] Mahmood H, Tripathi M, Pugno N, Pegoretti A (2016) Enhancement of interfacial adhesion in glass fiber/epoxy composites by electrophoretic deposition of graphene oxide on glass fibers. Compos Sci Technol 126:149-157. https://d oi.org/10.1016/j.compscitech.2016.02.016

[12] Du X, Zhou H, Sun W, Liu HY, Zhou G, Zhou H et al (2017) Graphene/epoxy interleaves for delamination toughening and monitoring of crack damage in carbon fibre/epoxy composite laminates. Compos Sci Technol 140:123-133. h ttps://doi.org/10.1016/j.compscitech.2016.12.028

[13] Wang C, Li J, Yu J, Sun S, Li X, Xie F et al (2017) Grafting of size-controlled graphene oxide sheets onto carbon fiber for reinforcement of carbon fiber/epoxy composite interfacial strength. Compos Part A Appl Sci Manuf 101:511-520. h ttps://doi.org/10.1016/j.compositesa.2017.07.015

[14] Kwon YJ, Kim Y, Jeon H, Cho S, Lee W, Lee JU (2017) Graphene/carbon nanotube hybrid as a multi-functional interfacial reinforcement for carbon fiber-reinforced composites. Compos Part B Eng 122:23-30. https://doi.org/10. 1016/j.compositesb.2017.04.005

[15] Umer R (2018) Manufacturing and mechanical properties of graphene coated glass fabric and epoxy composites. J Compos Sci 2(2),17:1-15. https://doi.org/10.3390/jcs2020017

[16] Eaton MJ, Ayre W, Williams M, Pullin R, Evans SL (2014) Nano-reinforcement of resin infused carbon fibre laminates reinforced using carbon nano-tubes and graphene. In: 16th Int Conf Exp Mech. Cambridge (UK). https://doi.org/10.13 140/2.1.1006.3368

[17] Papageorgiou DG, Kinloch IA, Young RJ (2017) Mechanical properties of graphene and graphene-based nanocomposites. Prog Mater Sci 90:75-127. https://doi.org/10.1016/j.pmatsci. 2017.07.004

[18] Jiang S, Li Q, Wang J, He Z, Zhao Y, Kang M (2016) Multiscale graphene oxide-carbon fiber reinforcements for advanced polyurethane composites. Compos Part A Appl Sci Manuf 87:1-9. https://doi.org/10.1016/j.compositesa.2016.0 4.004

[19] Young RJ, Kinloch IA, Gong L, Novoselov KS (2012) The mechanics of graphene nanocomposites: a review. Compos Sci Technol 72(12):1459-1476. https://doi.org/10.1016/j.co mpscitech.2012.05.005

[20] Pathak AK, Borah M, Gupta A, Yokozeki T, Dhakate SR (2016) Improved mechanical properties of carbon fiber/graphene oxide-epoxy hybrid composites. Compos Sci Technol 135:28-38. https://doi.org/10.1016/j.compscitech.2 016.09.007

[21] Qin W, Vautard F, Drzal LT, Yu J (2015) Mechanical and electrical properties of carbon fiber composites with 
incorporation of graphene nanoplatelets at the fiber-matrix interphase. Compos Part B Eng 69:335-341. https://doi.org/ 10.1016/j.compositesb.2014.10.014

[22] Monfared Zanjani JS, Okan BS, Menceloglu YZ, Yildiz M (2016) Nano-engineered design and manufacturing of highperformance epoxy matrix composites with carbon fiber/selectively integrated graphene as multi-scale reinforcements. RSC Adv 6(12):9495-9506. https://doi.org/10.1039/ C5RA23665G

[23] Zhang H, Liu Y, Huo S, Briscoe J, Tu W, Picot OT et al (2017) Filtration effects of graphene nanoplatelets in resin infusion processes: problems and possible solutions. Compos Sci Technol 139:138-145. https://doi.org/10.1016/j.co mpscitech.2016.12.020

[24] Zhang H, Liu Y, Kuwata M, Bilotti E, Peijs T (2015) Improved fracture toughness and integrated damage sensing capability by spray coated CNTs on carbon fibre prepreg. Compos Part A Appl Sci Manuf 70:102-110. https://doi.org/ 10.1016/j.compositesa.2014.11.029

[25] Young RJ, Liu M, Kinloch IA, Li S, Zhao X, Vallés C et al (2018) The mechanics of reinforcement of polymers by graphene nanoplatelets. Compos Sci Technol 154:110-116. https://doi.org/10.1016/j.compscitech.2017.11.007

[26] Prusty RK, Ghosh SK, Rathore DK, Ray BC (2017) Reinforcement effect of graphene oxide in glass fibre/epoxy composites at in-situ elevated temperature environments: an emphasis on graphene oxide content. Compos Part A Appl Sci Manuf 95:40-53. https://doi.org/10.1016/j.compositesa. 2017.01.001

[27] Berry V (2013) Impermeability of graphene and its applications. Carbon 62:1-10. https://doi.org/10.1016/j.carbon.2 013.05.052

[28] Cataldi P, Athanassiou A, Bayer IS (2018) Graphene nanoplatelets-based advanced materials and recent progress in sustainable applications. Appl Sci 8(9),1438:1-35. https://d oi.org/10.3390/app8091438

[29] Jang BZ, Zhamu A (2008) Processing of nanographene platelets (NGPs) and NGP nanocomposites: a review. J Mater Sci 43(15):5092-5101. https://doi.org/10.1007/s10 853-008-2755-2

[30] Honaker K, Vautard F, Drzal LT (2017) Investigating the mechanical and barrier properties to oxygen and fuel of high density polyethylene-graphene nanoplatelet composites. Mater Sci Eng B Solid-State Mater Adv Technol 216:23-30. https://doi.org/10.1016/j.mseb.2016.10.005

[31] Checchetto R, Miotello A, Nicolais L, Carotenuto G (2014) Gas transport through nanocomposite membrane composed by polyethylene with dispersed graphite nanoplatelets. J Memb Sci 463:196-204. https://doi.org/10.1016/j.memsci. 2014.03.065
[32] Raine TP, Istrate OM, King BE, Craster B, Kinloch IA, Budd PM (2018) Graphene/polyamide laminates for supercritical $\mathrm{CO}_{2}$ and $\mathrm{H}_{2} \mathrm{~S}$ barrier applications: an approach toward permeation shutdown. Adv Mater Interfaces 5(15),1800304:1-6. https://doi.org/10.1002/admi.201800 304

[33] Al-Jabareen A, Al-Bustami H, Harel H, Marom G (2013) Improving the oxygen barrier properties of polyethylene terephthalate by graphite nanoplatelets. J Appl Polym Sci 128(3):1534-1539. https://doi.org/10.1002/app.38302

[34] Kalaitzidou K, Fukushima H, Drzal LT (2007) Multifunctional polypropylene composites produced by incorporation of exfoliated graphite nanoplatelets. Carbon 45(7):1446-1452. https://doi.org/10.1016/j.carbon.2007.03. 029

[35] Liu M, Cataldi P, Young RJ, Papageorgiou DG, Kinloch IA (2021) High-performance fluoroelastomer-graphene nanocomposites for advanced sealing applications. Compos Sci Technol 202,108592:1-9. https://doi.org/10.1016/j.com pscitech.2020.108592

[36] Zhang Q, Wang YC, Bailey CG, Istrate OM, Li Z, Kinloch IA et al (2019) Quantification of gas permeability of epoxy resin composites with graphene nanoplatelets. Compos Sci Technol 184,107875:1-11. https://doi.org/10.1016/j.compsc itech.2019.107875

[37] Cui Y, Kundalwal SI, Kumar S (2016) Gas barrier performance of graphene/polymer nanocomposites. Carbon 98:313-333. https://doi.org/10.1016/j.carbon.2015.11.018

[38] Wu H, Drzal LT (2012) Graphene nanoplatelet paper as a light-weight composite with excellent electrical and thermal conductivity and good gas barrier properties. Carbon 50(3):1135-1145. https://doi.org/10.1016/j.carbon.2011.10. 026

[39] Kalinkin DA, Belova OV, Andreev RO (2018) Investigation of gas permeability of fibrous composite material in a vacuum. In: AIP Conf Proc.; 2007(August). https://doi.org/10. 1063/1.5051895

[40] Defauchy V, Le Corre H, Colin X (2018) Simulation of the oxygen permeability of a composite container. J Compos Sci 2(2),21:1-14. https://doi.org/10.3390/jcs2020021

[41] Khoe C, Sen R, Bhethanabotla VR (2011) Oxygen permeability of fiber-reinforced polymers. J Compos Constr 15(4):513-521. https://doi.org/10.1061/(ASCE)CC.1943-56 14.0000187

[42] Silvanius M, Frånberg O (2021) Permeability properties of a pressure induced compacted polymer liner in gas cylinder. J Appl Polym Sci 138(18):1-11. https://doi.org/10.1002/app. 50335

[43] Flanagan M, Grogan DM, Goggins J, Appel S, Doyle K, Leen SB et al (2017) Permeability of carbon fibre PEEK 
composites for cryogenic storage tanks of future space launchers. Compos Part A Appl Sci Manuf 101:173-184. h ttps://doi.org/10.1016/j.compositesa.2017.06.013

[44] Hamori H, Kumazawa H, Higuchi R, Yokozeki T (2020) Gas permeability of CFRP cross-ply laminates with thin-ply barrier layers under cryogenic and biaxial loading conditions. Compos Struct 245,112326:1-7. https://doi.org/10.10 16/j.compstruct.2020.112326

[45] Choi S, Sankar BV (2008) Gas permeability of various graphite/epoxy composite laminates for cryogenic storage systems. Compos Part B Eng 39(5):782-791. https://doi.org/ 10.1016/j.compositesb.2007.10.010

[46] Ebina T, Ishii R, Aizawa T, Yoshida H (2017) Development of clay-based film and its application to gas barrier layers of composite tanks. J Japan Pet Inst 60(3):121-126. https://doi. org/10.1627/jpi.60.121

[47] Yonemoto K, Yamamoto Y, Okuyama K, Ebina T (2009) Application of CFRP with high hydrogen gas barrier characteristics to fuel tanks of space transportation system. Trans Japan Soc Aeronaut Sp Sci Sp Technol Japan 7(ists26):13-18. https://doi.org/10.2322/tstj.7.Pc_13

[48] McVay AC, Johnson WS (2010) Permeability of various hybrid composites subjected to extreme thermal cycling and low-velocity impacts. J Compos Mater 44(12):1517-1531. h ttps://doi.org/10.1177/0021998309353957

[49] Findley BC, Johnson WS (2003) Benefits of surface coatings for impacted composites to be used for cryogenic tankage. In: 44th AIAA/ASME/ASCE/AHS/ASC Struct Struct Dyn Mater Conf. (April). https://doi.org/10.2514/6.2003-1938

[50] Chu J, Young RJ, Slater TJA, Burnett TL, Coburn B, Chichignoud L et al (2018) Realizing the theoretical stiffness of graphene in composites through confinement between carbon fibers. Compos Part A Appl Sci Manuf 113:311-317. https://doi.org/10.1016/j.compositesa.2018.07.032

[51] Lin Y-H, Yang C-Y, Lin S-F, Lin G-R (2015) Triturating versatile carbon materials as saturable absorptive nano powders for ultrafast pulsating of erbium-doped fiber lasers. Opt Mater Expr 5(2):236-253. https://doi.org/10.1364/OME. 5.000236

[52] Ferrari AC, Meyer JC, Scardaci V, Casiraghi C, Lazzeri M, Mauri F et al (2006) Raman spectrum of graphene and graphene layers. Phys Rev Lett 97(18):1-4. https://doi.org/ 10.1103/PhysRevLett.97.187401

[53] Venturi F, Hussain T (2020) Radial injection in suspension high velocity oxy-fuel (S-HVOF) thermal spray of graphene nanoplatelets for tribology. J Therm Spray Technol 29(1-2):255-269. https://doi.org/10.1007/s11666-019-0095 $7-\mathrm{y}$

[54] Truong GT, Van TH, Choi KK (2019) Tensile behavior of carbon fiber-reinforced polymer composites incorporating nanomaterials after exposure to elevated temperature. J Nanomater 2019,4139208:1-14. https://doi.org/10.1155/2 $019 / 4139208$

[55] Moaseri E, Karimi M, Maghrebi M, Baniadam M (2014) Fabrication of multi-walled carbon nanotube-carbon fiber hybrid material via electrophoretic deposition followed by pyrolysis process. Compos Part A Appl Sci Manuf 60:8-14. https://doi.org/10.1016/j.compositesa.2014.01.009

[56] Joshi M, Adak B, Butola BS (2018) Polyurethane nanocomposite based gas barrier films, membranes and coatings: a review on synthesis, characterization and potential applications. Prog Mater Sci 97:230-282. https://doi.org/ 10.1016/j.pmatsci.2018.05.001

[57] Van Rooyen LJ, Karger-Kocsis J, David KL (2015) Improving the helium gas barrier properties of epoxy coatings through the incorporation of graphene nanoplatelets and the influence of preparation techniques. J Appl Polym Sci 132(39):1-13. https://doi.org/10.1002/app.42584

[58] Nielsen LE (1967) Models for the permeability of filled polymer systems. J Macromol Sci Part A: Chem 1(5):929-942. https://doi.org/10.1080/10601326708053745

[59] Liu M, Papageorgiou DG, Li S, Lin K, Kinloch IA, Young RJ (2018) Micromechanics of reinforcement of a graphenebased thermoplastic elastomer nanocomposite. Compos Part A Appl Sci Manuf 110:84-92. https://doi.org/10.1016/j.co mpositesa.2018.04.014

Publisher's Note Springer Nature remains neutral with regard to jurisdictional claims in published maps and institutional affiliations. 